$\begin{array}{ll} & \text { Etnográfica } \\ \text { etnográfica } & \text { Revista do Centro em Rede de Investigação em }\end{array}$

Antropologia

vol. 21 (1) | 2017

Vol. 21 (1)

\title{
A regulação ética da investigação e os desafios postos às práticas etnográficas
}

Research ethics regulations and its pitfalls for ethnographic practices

\section{Marta Roriz e Cristina Padez}

\section{(2) OpenEdition}

\section{Journals}

Edição electrónica

URL: https://journals.openedition.org/etnografica/4820

DOI: 10.4000/etnografica.4820

ISSN: 2182-2891

\section{Editora}

Centro em Rede de Investigação em Antropologia

\section{Edição impressa}

Data de publição: 1 fevereiro 2017

Paginação: 75-95

ISSN: 0873-6561

\section{Refêrencia eletrónica}

Marta Roriz e Cristina Padez, «A regulação ética da investigação e os desafios postos às práticas etnográficas», Etnográfica [Online], vol. 21 (1) | 2017, posto online no dia 13 março 2017, consultado o 10 fevereiro 2022. URL: http://journals.openedition.org/etnografica/4820 ; DOl: https://doi.org/ 10.4000/etnografica.4820

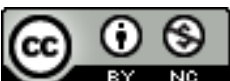

Etnográfica is licensed under a Creative Commons Attribution-NonCommercial 4.0 International License. 


\section{A regulação ética da investigação e os desafios postos às práticas etnográficas}

\section{Marta Roriz e Cristina Padez}

Face à crescente tendência de institucionalização de mecanismos de regulação ética da investigação com sujeitos humanos, discute-se com este artigo os impactos que a regulação prospetiva dos projetos de investigação tem tido nas ciências sociais e, mais concretamente, os desafios que tem colocado à investigação etnográfica. A partir de uma revisão histórica, quer da origem da regulação ética da investigação quer da própria antropologia, analisa-se o que se constitui como ética na prática etnográfica, salientando as incomensurabilidades que este tipo de investigação tem encontrado nos modelos de regulação fundados na ética biomédica. Através de noções como a noção de risco ou da primazia do princípio de consentimento informado, ilustra-se como é mobilizado um entendimento da investigação com humanos que é redutor para a investigação social, qualitativa e etnográfica, substancialmente diferente da investigação das ciências exatas ou da experimentação clínica.

PALAVRAS-CHAVE: ética, investigação etnográfica, regulação, IRB, consentimento informado.

Research ethics regulations and its pitfalls for ethnographic practices - Given the growing tendency of institutionalizing regulatory ethical procedures for research with human subjects, this article discusses the impacts of prospective research in the social sciences, and in particular in ethnographic research. Departing from a historic revision both of research regulation and of anthropology, we analyze what constitutes ethics in ethnographic practice, highlighting the incommensurability that this type of research has been facing in biomedical-based regulation models. Through notions such as risk and the primacy of informed consent we illustrate how the understanding of research with human subjects being mobilized is a reducing one when looked from the angle of social, qualitative or ethnographic research, which is substantially different from research in exact sciences or clinical experimentation.

KEYWORDS: ethics, ethnographic research, regulation, IRB, informed consent.

RORIZ, Marta (martaroriz2006@gmail.com) - CIAS, Departamento de Ciências da Vida, Universidade de Coimbra, 30004-5 16 Coimbra, Portugal.

PADEZ, Cristina (cpadez@gmail.com) - CIAS, Departamento de Ciências da Vida, Universidade de Coimbra, 30004-5 16 Coimbra, Portugal. 


\section{INTRODUÇÃO}

Nos últimos anos tem-se assistido a uma proliferação de diferentes debates sobre ética, tal é a explosão discursiva em torno do tema. Hoje em dia é comum ouvir-se falar da ética em todas as dimensões da sociedade. Desde as grandes questões da bioética presentes no espaço público, especialmente as questões postas pelos desenvolvimentos tecnológicos, ao meio empresarial, no qual se ouve falar da responsabilidade social e da corporate ethics e ainda no espaço económico, onde são comuns os apelos aos produtos e consumo éticos. $\mathrm{Na}$ antropologia, esta discursividade, por certos contágios e mesmo por obrigação, não é exceção. Fala-se da ethical turn na disciplina, tal tem sido a produção de conhecimento em torno do tema, assim como dos debates acerca do que se constitui como ética na investigação social face à crescente regulação da investigação já em marcha em diferentes países.

Este artigo pretende oferecer, por um lado, uma revisão sobre a regulação da investigação em contextos como os Estados Unidos da América (EUA) e o Reino Unido, focando a institucionalização dos procedimentos de revisão e regulação ética da investigação já em prática em diferentes países, com constituição de órgãos para esse fim, e, por outro lado, fazer uma revisão aos debates em torno da ética na prática etnográfica e na investigação social, focando em particular os problemas e incomensurabilidades que o modelo atual de regulação da investigação tem colocado à prática etnográfica. ${ }^{1}$

No que diz respeito à regulação ética da investigação, há hoje uma diversidade de abordagens que difere de acordo com os contextos nacionais (Bartlett 2008). Há países, como os EUA, o Reino Unido e ainda o Brasil, onde os institutional research boards (IRB) ou os research ethics committees (REC) e os comités de ética em pesquisa (CEP) - corpos cujo objetivo é avaliar a adequação ética dos projetos de investigação que envolvam sujeitos humanos - estão bem estabelecidos e institucionalizados nas universidades, e há países onde esta regulação e órgãos só existem para a investigação biomédica, como é o caso de vários países europeus, como Portugal, Espanha, Itália, Holanda, entre tantos outros. Embora numa grande parte dos países esta obrigação de submissão dos projetos de investigação a uma avaliação ética seja inexistente, há fatores que poderão alterar este cenário. Um deles é a tendência para a investigação ser cada vez mais financiada globalmente por instituições que se reveem num modelo de regulação; outro fator é, por exemplo, a tendência

l Este artigo tem, em parte, origem numa pesquisa e num working paper apresentado no encontro "Ethics and Methodological Pitfalls in Health Research" organizado pela European Sociological Association, mais concretamente a rede RN16 Sociology of Health and Illness, a 27 de agosto de 2014, em Helsínquia. Foi ainda possível escrevê-lo graças ao apoio e financiamento da Fundação para a Ciência e a Tecnologia, através de uma bolsa de doutoramento, assim como ao apoio de uma bolsa de viagem concedida pela European Sociological Association. 
para a harmonização de políticas e práticas entre os diferentes contextos nacionais dentro da União Europeia. Nesta medida, e face a esta tendência, pretendemos com este artigo analisar as experiências dos contextos em que a regulação da investigação que envolve sujeitos humanos está em prática, focando em particular o impacto que a regulação nestes moldes tem tido para a investigação das ciências sociais em geral, e para as práticas etnográficas mais concretamente. Nas próximas secções pretende-se, primeiro, fazer uma breve incursão à origem da regulação da investigação, partindo da criação do Código de Nuremberga em 1947 até à atualidade da institucionalização da revisão prospetiva para todo o tipo de investigação que envolva sujeitos humanos; e, segundo, focar em concreto os desafios que esta regulação e revisão tem posto à investigação etnográfica e como diferentes noções do que se constitui como ética são mobilizadas. Partindo de uma análise às características e natureza da investigação etnográfica, oferece-se uma reflexão acerca da adequação da noção de risco e do princípio de consentimento informado, pilares na base do modelo de regulação da investigação, e do que estes podem significar no trabalho etnográfico.

\section{A REGULAÇÃO ÉTICA EM INVESTIGAÇÃO:} DO CÓDIGO DE NUREMBERGA À REVISÃO PROSPETIVA INSTITUCIONAL

Falar de princípios éticos ou regulação ética da investigação implica que falemos na sua origem, o Código de Nuremberga estabelecido em 1947. Este código, um conjunto de princípios éticos para a experimentação humana criado na sequência dos julgamentos de Nuremberga, após a Segunda Guerra Mundial, tornou-se o texto fundacional para os subsequentes acordos internacionais sobre a investigação que envolva sujeitos humanos. A sua criação teve origem nas revelações feitas sobre as experiências nazis com prisioneiros dos campos de concentração (Lifton 2000). Mais tarde, com a Declaração de Helsínquia, criada pela Associação Médica Mundial em 1964, elaborou-se um conjunto de princípios éticos universalistas a aplicar aos participantes na investigação médica visando a sua proteção, que inclui princípios como o consentimento informado, o respeito da confidencialidade e a proteção da vida humana (WMA 2008). ${ }^{2}$

Estes documentos são ainda hoje a base e guia da conduta de práticas de todos os tipos de investigação que envolva sujeitos humanos. O consentimento informado tornou-se condição e prática sine qua non na investigação médica

2 A Declaração de Helsínquia já teve seis revisões, a última em 2008. Surgiu como o primeiro esforço da comunidade médica para regulamentar a investigação. É hoje o padrão internacional para a investigação biomédica, servindo ainda de base para muitos outros documentos (ver mais em WMA 2008). 
e está incorporado na legislação da maioria dos países. A sua influência, contudo, assim como dos restantes princípios, alargou-se para além da investigação clínica. O modelo de regulação da investigação e de proteção de sujeitos envolvidos na investigação biomédica tem sido apresentado como modelo para todas as outras formas de investigação envolvendo sujeitos humanos, nomeadamente entre as ciências sociais, aparecendo ainda nos códigos de práticas de quase todas as organizações profissionais, agências de financiamento e instituições envolvidas com a investigação (Boulton e Parker 2007; Parker 2007; Macdonald e Spiegel 2013; Nunes 2011).

A necessidade de regular a investigação que envolve sujeitos humanos originou-se então a partir dos vários casos de abusos no passado. Alguns destes casos foram tão graves e controversos que despoletaram várias transformações durante a segunda metade do século XX. Assistiu-se a uma proliferação da criação de códigos de ética profissionais, para diferentes classes de profissionais, assim como à criação de comissões de ética institucionais, e ainda a um crescente processo de institucionalização em vários contextos, especialmente nos países do Norte, de regras e procedimentos de revisão por parte de comissões externas como os IRB, REC, CEP e outros equivalentes como se conhecem hoje. Nos EUA, um dos casos de abuso mais mediáticos foi o caso de Tuskegee, um estudo de sífilis conduzido ao longo de mais de 40 anos pelo Serviço de Saúde Pública americano, no qual homens afro-americanos no Alabama rural ficaram deliberadamente impedidos de aceder a um tratamento para a sífilis sob o propósito de melhorar o conhecimento público acerca da história natural da doença. O mediatismo em torno do caso levou à aprovação do National Research Act de 1974 e posteriormente, em 1981, o Congresso americano aprovou o que veio a ficar conhecido como a Common Rule, regulamentação para toda a investigação financiada por dinheiro federal que estabelece uma série de requisitos e obrigações legais, entre os quais a aprovação por uma comissão de investigação institucional, um IRB. A emergência dos IRB nos EUA, ${ }^{3}$ expoente máximo desta tendência, tem vindo a definir grande parte do cenário da revisão ética noutros contextos. Isto deve-se, entre outros fatores, ao facto de muito do financiamento para a investigação internacional estar ligado a instituições americanas, de que são exemplos o National Institute of Health (NIH) ou os Centers for Disease Control and Prevention (CDC), entre muitas outras agências financiadoras. Consequentemente, muita da investigação internacional fica sujeita aos moldes adotados neste país para a supervisão ética, na maior parte das vezes seguindo e aplicando uma perspetiva médico-científica da investigação.

3 Para mais detalhe sobre os procedimentos burocráticos e a regulação ética dos IRB, ver Lederman (2006a). 
A regulamentação ética que se estipulou para a experimentação e investigação clínica com sujeitos humanos tem vindo a servir de base para a regulação de todo o tipo de investigação que envolva sujeitos humanos. Isto cria uma distorção, na medida em que nem todo o tipo de investigação que lida com sujeitos humanos o faz numa perspetiva biomédica ou clínica, mas a orientação que regula a investigação em geral, onde se incluem as ciências sociais e humanas, tem as suas bases na ética biomédica. A par desta questão ligada ao financiamento global por parte dessas agências que exigem a regulação ética da investigação nestes moldes, há ainda mudanças políticas e estruturais ligadas à própria governação da ciência que estão a pôr desafios aos métodos das ciências sociais e, em particular, às práticas etnográficas. Alguns antropólogos têm desenvolvido a noção de audit society (Shore e Wright 1999; Strathern 2000) para falar de uma cultura latente no ensino superior dos últimos anos, onde um regime cada vez mais rigoroso de auditoria e inspeção - sob o propósito da manutenção da qualidade, seletividade da investigação, revisões das aulas, etc. - foi instituído. Alguns autores identificam que a ética, as revisões éticas e as comissões de ética que se têm formado nas instituições de investigação e de ensino, na forma de IRB, REC, etc., são precisamente uma extensão desta nova cultura ligada à noção de audit society (Pels 1999; Strathern 2000).

Mas, como afirmávamos atrás, há, de acordo com diferentes contextos, uma diversidade de abordagens no que diz respeito à regulação ética da investigação (Bartlett 2008). Se, por um lado, países como os EUA, o Reino Unido e ainda o Brasil - país este onde a antropologia, em particular por intermédio da Associação Brasileira de Antropologia ( $\mathrm{ABA}$ ), tem liderado a discussão sobre a regulação ética na pesquisa das ciências sociais ${ }^{4}$ - institucionalizaram estes organismos regulatórios nas suas universidades, no caso europeu, dentro da União Europeia, existem variações, apesar de a tendência ser no sentido da harmonização das diferentes agências de financiamento nacionais, das associações profissionais e dos códigos de ética para a investigação definidos para cada país. ${ }^{5}$ Apesar das tendências neste sentido, no que diz respeito aos códigos de ética profissionais, há na antropologia alguma resistência a adotar estes códigos e guidelines de conduta para a investigação antropológica, talvez por os códigos de ética serem gerais e absolutos. Como De Laine (2000: 4) afirma, estes códigos são construções intelectualizadas e objetivas que não permitem variações culturais, sociais, pessoais e

4 Para mais detalhes sobre o estudo de caso brasileiro, e o seu debate público da regulação em pesquisa das ciências sociais, visto que não há espaço neste artigo à sua análise em detalhe, consultar Fonseca (2015), Fleischer e Schuch (2010), Duarte (2004, 2014, 2015), Machado (2007), Ribeiro (2006), Sarti (2015), Sarti e Duarte (2013), Víctora et al. (2004).

5 Para mais detalhes sobre os diferentes códigos na Europa em comparação com o contexto britânico, consultar o working paper de Lewis et al. (2004). 
emocionais. Ao contrário da Associação Americana de Antropologia (AAA), que teve este debate há já alguns anos, tendo criado o seu próprio código assim como princípios de responsabilidade profissional, ${ }^{6}$ ou da Associação Brasileira de Antropologia, ${ }^{7}$ a Associação Europeia de Antropólogos Sociais (EASA) não tem um código estabelecido, embora tenha uma rede de investigação dedicada à ética, que fornece aconselhamento ao seu conselho executivo quando há necessidade. ${ }^{8} \mathrm{O}$ mesmo acontece no contexto nacional português: não existe um código oficial de conduta ética estipulado pela Associação Portuguesa de Antropologia (APA). Ao contrário do que se passa no Reino Unido e nos EUA, que, além de terem códigos profissionais ou guidelines de práticas estabelecidas, têm os IRB e REC nas instituições de investigação bem estabelecidos, em Portugal, Holanda, Itália, entre muitos outros países onde esta revisão prospetiva não existe, não temos de, como investigadores ou estudantes, identificar a priori as implicações éticas do nosso trabalho, preencher formulários e seguir as investigações com base nos princípios do consentimento informado. ${ }^{9}$ As obrigatoriedades impostas pelos procedimentos formais de avaliação ética por parte destas comissões, sejam as das instituições de investigação ou as das agências de financiamento nacionais, têm causado muito debate e inclusive problemas e bloqueios à investigação etnográfica. Estes problemas têm estado na base de uma série de publicações e reflexões acerca do que se constitui como ética na etnografia. Torna-se importante, portanto, ter em conta estas experiências, assim como os problemas e desafios que esta regulação ética, nos moldes em que é feita, trouxe à prática etnográfica, principalmente nos países onde a revisão prospetiva não existe, ${ }^{10}$ de maneira a que, na eventualidade da sua institucionalização, a nossa comunidade de prática (Lave e Wenger 1991) como antropólogos e etnógrafos esteja concertada e se faça representar.

6 O código de ética da AAA está disponível em < http://ethics.americananthro.org >, onde existe ainda um fórum sobre ética e os princípios de responsabilidade profissional.

7 A ABA tem um código de ética para o antropólogo e antropóloga criado em 1986 e revisto em 2012, disponível em <http://www.abant.org.br/?code=3.1 > .

8 Consultar < http://www.easaonline.org/networks/ethics/ > .

9 Nestes contextos, e em Portugal, apenas a investigação biomédica está sujeita a regulação, havendo, nas faculdades de Medicina e nos centros de investigação biomédica ou clínica, comissões de ética para o efeito. Também os hospitais têm as suas comissões de ética, onde todos os projetos que aí tomem lugar, mesmo os de ciências sociais, estão sujeitos a uma avaliação por parte desses órgãos.

10 Há, contudo, uma possibilidade de vir a existir, quer na Europa quer em vários países em desenvolvimento, por pressões externas, nomeadamente devido ao crescente financiamento global da investigação e aos modelos de governação científica, a adoção de protocolos éticos, não apenas para a investigação biomédica, que tem uma história no que diz respeito a este tipo de regulação, mas também nas ciências sociais (Freed-Taylor 1994; Fassin 2006; Lederman 2006a, 2006b; Macdonald e Spiegel 2013; Simpson 2011). 


\section{A REGULAÇÃO ÉTICA E A INVESTIGAÇÃO DAS CIÊNCIAS SOCIAIS:} AS PARTICULARIDADES DA PRÁTICA ETNOGRÁFICA

Apesar da intensificação discursiva em torno da ética nestes últimos anos, os debates em torno do tema na antropologia não são novos. Como demonstra Caplan (2003b), na revisão histórica que faz, pode notar-se uma intensificação da discussão ética na antropologia sempre que a disciplina sofre transformações paradigmáticas. ${ }^{11}$ Ou seja, é nos momentos em que as fronteiras da disciplina são redefinidas que o discurso sobre ética se intensifica e é, portanto, nestes momentos que, enquanto antropólogos, também nos constituímos como comunidade moral. Sempre que a disciplina se debatia nas suas bases, de que são exemplos as transformações nas décadas de 1960 e 1970 com os movimentos civis nos EUA, as descolonizações e a influência destes acontecimentos na teoria antropológica, com o pós-modernismo e ainda a viragem do milénio, todas estas transformações tectónicas na antropologia foram acompanhadas pelo debate da ética na disciplina. Representativo da preocupação ética foi, por exemplo, o debate em torno do código de ética da AAA, em resposta a certos desenvolvimentos na disciplina, muito marcado por episódios como a crise do Projeto Camelot nos EUA ou ainda pela entrada dos alunos na antropologia aplicada (Fluehr-Lobban 1991; Pels 1999). ${ }^{12}$ Episódios como o Projeto Camelot e outras transformações sociais levaram a que várias associações profissionais de antropólogos, sociólogos e outros profissionais adotassem códigos de ética ou guidelines de conduta que definem os deveres e responsabilidades dos cientistas sociais. Como expõe Caplan (2003b), os cientistas sociais não só têm de se comportar eticamente como também têm de ser reconhecidos como estando a agir eticamente, quer seja pelos sujeitos da investigação, quer por colegas, alunos, financiadores e comissões de ética. Para muitos, isto consegue-se através da adesão a um código de ética profissional; contudo, esta não é uma questão pacífica, uma vez que tais códigos são regularmente contestados na sua formulação e o acordo quanto à sua interpretação também é problemático (Caplan 2003b). Alguns autores têm apontado uma certa resistência por parte dos cientistas sociais a acomodaram-se a este tipo de regulação. Não se

11 Para uma revisão detalhada ou apanhado histórico dos debates sobre ética na antropologia aquando das principais mudanças paradigmáticas da disciplina - período pós-colonial, feministas, pós-modernismo, a viragem do milénio, etc. -, ver Caplan (2003a, 2003b) e Pels (1999).

12 O Projeto Camelot foi um estudo realizado pelo exército norte-americano, pelo seu gabinete de operações especiais que, em plena Guerra Fria, em 1964, reuniu uma série de cientistas sociais, como antropólogos, sociólogos, psicólogos, economistas e outros intelectuais, tendo em vista a análise cultural de diferentes países e a criação de um modelo de análise de sistemas sociais que detetasse a contrainsurgência. O objetivo era melhorar a capacidade do exército para prever, assim como influenciar, certos desenvolvimentos nesses países. Foi um projeto muito polémico, tido como imperialista, que fez acender o debate acerca das obrigações morais dos antropólogos e outros intelectuais. Para mais detalhe sobre o caso, ver, por exemplo, Solovey (2001). 
trata aqui de uma recusa de algum tipo de regulação do ponto de vista ético - aliás, a ética foi sempre vista como qualidade inerente à antropologia, uma virtude incorporada dos investigadores (Fassin 2006) -, antes são contestadas as formas como as exigências processuais e burocráticas dos IRB, nos contextos onde funcionam, podem deslocar os esforços realmente necessários para resolver os dilemas éticos sérios que são postos pela etnografia (Bosk e De Vries 2004), além de poderem criar obstáculos à liberdade de investigação e à viabilidade de certos tipos de pesquisa.

A ética costumava ser vista como uma virtude incorporada dos investigadores (Fassin 2006) e não como um conjunto de práticas normativas ou uma forma de regular a investigação. Os desafios éticos apareciam por norma associados às experiências do trabalho de campo e aos dilemas da investigação situada. A prática etnográfica na antropologia tem sido, ao longo da sua história, explícita ou implicitamente "ética", pois trata, na sua base, de falar sobre o "outro", incorporando assim dimensões éticas dessa prática. Contudo, nos últimos anos, é de notar também uma tendência para pensar as obrigações morais do antropólogo para com os seus sujeitos de investigação (Scheper-Hughes 1995; Battaglia 1999; Pels e Meskell 2005). A "viragem ética", como tem sido mencionada na antropologia, emerge, nesta medida, quer a partir de debates internos na disciplina - com as mudanças de paradigma dentro da antropologia, o reconhecimento de que a própria história da antropologia foi pautada por valores, pelo colonialismo, a crise da representação, etc. - quer por desenvolvimentos externos a ela, de que são exemplo a institucionalização da regulação da investigação, as mudanças culturais do tecido científico e os próprios desenvolvimentos da investigação clínica e médica (Parker 2007; Nunes 201 1; Boulton e Parker 2007; De Laine 2000; Fassin 2006; Guillemin e Gillam 2004).

Desde que se instalaram os IRB para a proteção dos sujeitos humanos, tem havido aquilo a que Bruner (2004) e Lederman (2006b) chamam mission creep, ou seja, a ideia de que esta revisão e regulação ética se expandiu e generalizou além do propósito inicial, não para a proteção dos sujeitos, mas muito no sentido de evitar litígios e proteger as instituições. ${ }^{13} \mathrm{O}$ resultado desta regulação tem sido na prática, para muitos cientistas sociais, um verdadeiro obstáculo, resultando num aumento dos atrasos dos projetos de investigação, da burocracia e das dificuldades em obter aprovação para os seus projetos. ${ }^{14} \mathrm{Se}$, por um lado, estes desenvolvimentos são racionalizados em termos da qualidade ética na investigação, que tem de ser exigida, as universidades também estão

13 A expressão anglo-saxónica mission creep descreve a expansão de um projeto ou missão para além dos seus objetivos originais, normalmente considerada indesejável por poder servir outros fins mais ambiciosos.

14 Para um caso examinado em detalhe, veja-se, por exemplo, Macdonald e Spiegel (2013). 
preocupadas com a possibilidade de ações legais, e veem a ética e o consentimento como formas de evitar o litígio. Há, portanto, claramente, como diz Caplan (2003b), uma política e uma economia da ética a ser mobilizadas.

Quando se discute ética na antropologia discute-se os principais aspetos da disciplina, desde a própria epistemologia às práticas do trabalho de campo. Quando falamos na regulação ética da investigação - que normalmente compreende a visão da ética fundada na ética biomédica - torna-se necessário pôr em evidência as particularidades do método etnográfico, pois falar de ética na investigação antropológica toca diretamente a forma como produzimos conhecimento.

Para os antropólogos, ou qualquer cientista social que use o método etnográfico, a principal ferramenta de recolha de dados são as relações que enceta com aqueles que são os participantes da sua investigação, ou os principais informantes do contexto sobre o qual se debruça. Normalmente não iniciamos a investigação com uma hipótese específica que testemos a posteriori de forma sistemática, como acontece nas ciências exatas. As situações com que o trabalho de campo nos confronta são substancialmente diferentes das encontradas na investigação biomédica, por exemplo. Como diz Fassin, "A etnografia não trata de sujeitos humanos em experiências clínicas. Mas sim seres sociais em circunstâncias históricas, incluindo o etnógrafo" (2006: 524).

Quando falamos em revisão prospetiva, seja na submissão de um projeto a um IRB ou a uma comissão de ética de um hospital, ${ }^{15}$ é muitas das vezes impossível indicar formalmente como vamos proceder, podendo apenas garantir a nossa presença no contexto do estudo, seja uma comunidade, um hospital ou um bairro, para o qual levamos as questões básicas que nos guiarão, assim como também não se consegue antever os "riscos" que podem advir dessa investigação. A investigação qualitativa e a etnográfica têm de ser vistas como um processo em aberto que implica que, em muitos casos, nem o investigador nem os participantes conseguem antecipar como a investigação irá desenvolver-se ou quais as questões que irão emergir, tornando impossível identificar a priori os riscos envolvidos na participação (Miller e Bell 2002; Boulton e Parker 2007). E a revisão prospetiva, com os seus formulários a que a proposta de investigação tem de ser ajustada, requer isso, que se identifique em detalhe o que será realizado em termos de investigação, assim como os riscos que essa investigação comporta. A ética na etnografia é algo tendencialmente emergente, algo que surge na prática, no decurso da investigação. Os dilemas éticos que encontramos no trabalho de campo são, nesta medida, diferentes das preo-

15 O atual projeto e trabalho de campo de Marta Roriz teve de ser sujeito ao exame da comissão de ética de um hospital central que tem regras e formulários próprios, documentos que se apresentam no fim deste artigo. Note-se que nestes documentos foram suprimidos os elementos que identificam a instituição. 
cupações éticas espelhadas nos procedimentos de revisão ética formais. Como sublinha Fabian (1991), muitas das questões de investigação emergem ex post factum, e como tal não podem ser antecipadas. Há, portanto, na investigação social, algumas incomensurabilidades com estes modelos éticos com base na ética biomédica. A noção de risco faz aqui pouco sentido. Como referem Boulton e Parker, "a investigação social pode ser intrusiva mas não é invasiva e tende a não envolver danos físicos, prejuízos ou morte. Os riscos sociais e psicológicos associados à investigação social não são diferentes daqueles encontrados no dia-a-dia e são riscos que devemos aceitar como o custo de vida numa sociedade livre: eles não requerem os mesmos tipos de proteção que requer a gestão de riscos físicos na investigação médica" (2007: 2190). Outro pilar base desta regulação e que é problemático é a noção de consentimento informado, que necessita ser pensada de forma diferente em etnografia. Como identifica Parker (2007), o consentimento tende a ser interpretado em termos antecipatórios, baseado na ideia de que as implicações, a metodologia, o objeto e questões da investigação podem ser previstos, discutidos e acordados antes do seu início (Parker 2007: 2252). Esta visão do consentimento informado é redutora, pois está relacionada com mudanças na prática médica, com desenvolvimentos tecnológicos da investigação biomédica e o crescente interesse nas implicações destes desenvolvimentos. Este domínio da ética, que envolve os debates públicos sobre as grandes questões postas pela bioética na sociedade (temas como a manipulação genética, a clonagem, a eutanásia e outros desenvolvimentos biotecnológicos) e o declínio da confiança que alguns escândalos na investigação biomédica provocaram, tem sido empurrado para o domínio da investigação social (Boulton e Parker 2007: 2188). Desta forma, a crítica a uma certa visão do consentimento informado tem sido bastante explorada, não só nas ciências sociais, mas também dentro da própria biomedicina.

As ciências sociais têm vindo a elaborar as suas próprias posições quanto ao significado e prática do consentimento informado, assim como aos modelos de práticas de investigação ética concebidos de uma forma geral, baseados em preocupações e métodos particulares de investigação social. Ao argumentar contra a imposição de um modelo de consentimento informado baseado no paradigma da investigação biomédica, os cientistas sociais têm frisado a distinção dos seus próprios paradigmas de investigação e as preocupações éticas que estes levantam. Ao apelar a estas diferenças, desafia-se a adequação e viabilidade do modelo biomédico de consentimento informado para a investigação social e qualitativa, reconhecendo que este tipo de trabalho tem importantes implicações éticas, para as quais são necessárias formas alternativas de ter em conta as vulnerabilidades e responsabilidade dos envolvidos na investigação (Boulton e Parker 2007: 2190).

Os antropólogos de forma geral veem o consentimento como algo negociado e processual. O princípio da observação participante implica deixar o 
controlo contextual na mão dos participantes na pesquisa. Como Lederman descreve, a prática da observação participante implica uma abertura sistemática à contingência, explora as implicações inesperadas geradas pelos participantes (2006b: 485). Há, portanto, na prática etnográfica, uma informalidade que lhe é característica. Informalidade essa que se refere àqueles momentos da prática etnográfica em que "investigação" e "vida quotidiana" são inextricáveis (Lederman 2006a). Fazer trabalho de campo é incorporarmo-nos nas situações sociais, que não são desenhadas pelo investigador social. É estar na situação. E esta informalidade exige uma atenção especial, pois tem sido problematizada nos EUA, onde os IRB supervisionam os investigadores e a sua conformidade com as regulações federais na pesquisa com humanos (2006a: 477).

É por trabalharmos imersos na situação social, que estudamos mas que não controlamos - a situação existe fora de nós -, que nos limitamos a observar, a registar e a participar (quando isso acontece). Nesta medida, informar os nossos sujeitos acerca dos riscos e benefícios em cooperarem connosco torna-se difícil, pois os riscos e os benefícios para os sujeitos não são diferentes dos que estão presentes numa interação normal com um estranho (Bosk e De Vries 2004). Os riscos de se ser um informador etnográfico não se põem ao nível dos riscos encontrados na investigação com experimentação - como o ensaio clínico, por exemplo. O que fazemos não é como a experimentação médica, que desenha um protocolo de investigação com o objetivo de o cumprir até ao fim (Bruner 2004).

Outro aspeto problemático é a exigência de assegurar a confidencialidade e anonimato dos sujeitos sob estudo, o que pode ser relativamente fácil de conseguir, mas que em algumas situações é mais difícil. Quem trabalha campos como a antropologia do poder e das elites, ou em domínios públicos, nem sempre pode garantir o anonimato. Por exemplo, alguém a investigar sobre o trabalho de um governo, seja a nível local ou do estado, que tenha de passar pela regulação ética nestes moldes, ficará paralisado (Bosk e De Vries 2004); certas controvérsias públicas ou mesmo científicas também não poderiam ser estudadas. Por outro lado, há pessoas que quando dão o seu testemunho querem ser identificadas, querem ter voz e exigem que o seu caso apareça identificado.

As preocupações e dilemas éticos são, em todos os tipos de investigação, parte da prática, e uma preocupação de qualquer investigador. Nos contextos em que a regulação ocorre, é útil a distinção de Guillemin e Gillam (2004) entre duas dimensões éticas: a ética processual e a ética na prática. A ética processual diria respeito a uma das primeiras fases do processo de investigação, em que se submete o projeto à autorização de uma comissão de ética, seja ela pertencente à instituição que promove a investigação ou à instituição onde o trabalho será desenvolvido (muitos de nós têm de passar por estas comissões quando a trabalhar em hospitais, por exemplo). Esta ética processual é vista como uma mera formalidade, um obstáculo que tem de se superar 
para avançar com o projeto. Envolve o uso de uma linguagem que a comissão entenda, livre de jargão, mas que em todo o caso assegure à comissão que somos competentes e investigadores com experiência que podem ser fiáveis. Isto envolve ainda explicar a metodologia a uma comissão que na maior parte das vezes não está familiarizada com os métodos qualitativos. Por outro lado, a ética na prática diz respeito às questões éticas que emergem no decurso da investigação, as reais questões que nos surgem no terreno. Estas questões normalmente não são visadas nas submissões às comissões de ética, nem são eventos que possam ser antevistos quando se pede aprovação. Estas situações constituem aquilo a que Guillemin e Gillam (2004) chamam "momentos eticamente importantes", que, não sendo previsíveis, enfrentamos durante o encontro etnográfico. Estes momentos eticamente importantes podem ser de vários tipos, encaixando ainda na noção de “microética”. Komesaroff (1995) propõe o termo microética para referir as questões éticas que surgem no dia-a-dia da prática clínica no âmbito do estabelecimento de uma relação de confiança entre médico e paciente, em situações como a recolha da história sexual, quando se lida com medos ou se ouve a experiência de doença do paciente, mas pode aqui ser também aplicado à dinâmica complexa entre o etnógrafo e o sujeito pesquisado. Os aspetos interpessoais da pesquisa e as interações entre o investigador e os sujeitos são uma importante dimensão ética da prática de investigação, pois é nestas interações que residem as possibilidades do respeito pela autonomia, dignidade e privacidade dos participantes e também os riscos de falhar com estas, causando assim potenciais danos para os participantes. É nestas interações que o processo de consentimento informado realmente ocorre (Guilleman e Gillam 2004: 275). Estes autores sugerem ainda que estas duas formas de ética, a processual e a ética na prática, têm uma continuidade entre si, e portanto não devem estar separadas. É ao nível da ética na prática que a noção de reflexividade se integra e se pode estender às preocupações da ética processual. Esta continuidade entre ambas consiste no facto de, embora a ética processual seja incapaz de informar e guiar todos os aspetos da prática de investigação (nomeadamente as situações relativas à microética), ela serve a função de nos obrigar a considerar e a refletir sobre os princípios fundamentais que regem a integridade da investigação (Guilleman e Gillam 2004: 277). Aqui a reflexividade torna-se uma forma de assegurar não apenas uma prática rigorosa da investigação, mas também uma prática que seja ética. Ser reflexivo num sentido ético significa reconhecer e estar sensibilizado para as dimensões microéticas da pesquisa, e ao fazê-lo ficamos alerta para as formas de lidar com as tensões éticas quando estas surgirem. Como Geertz afirmava, a etnografia é fundamentalmente um projeto interpretativo (1973) e isto é bem captado no conceito de reflexividade, característica da investigação social. Trata-se até de uma questão metodológica, pois envolve tomar responsabilidade pelos nossos processos de produção de conhecimento. 


\section{CONSIDERAÇÕES FINAIS}

Em jeito de conclusão, e como nos lembra Bruner (2004), a etnografia é uma conversa sustentada com outros, que inclui o diálogo, a observação e a participação ao longo de um período de tempo. O modelo em prática dos IRB implica que haja uma separação entre sujeito e objeto, como entre o médico e o paciente, mas na etnografia a linha separadora entre o observador e os observados é muitas vezes problemática. Quando se vive por longos períodos interligado com outros, imerso em certos contextos, é difícil separarmo-nos dos outros. A investigação não é algo que se separa facilmente de nós. Desde a criação dos IRB e organismos similares e deste aparato regulatório, o mundo tem mudado, tal como as estratégias metodológicas também se desenvolveram. A etnografia expandiu-se nos tópicos sobre os quais se debruça, tornou-se global e multissituada (Marcus 1995, 1998), focando quer fenómenos alargados quer populações em movimento. A estrutura de revisão dos IRB nos EUA, por exemplo, não se alterou tão rapidamente quanto a investigação etnográfica. Como resultado, os processos de revisão que tendem a disciplinar novas pesquisas e experimentações criam efeitos e consequências no trabalho etnográfico, especialmente entre os estudantes e investigadores mais jovens (Bruner 2004; Macdonald e Spiegel 2013).

Quando se analisa a vária literatura sobre o funcionamento dos IRB e demais casos (como o do Brasil, entre outros países) onde este modelo vingou e é aplicado nas ciências sociais, fica-se com a ideia de que, além de os sistemas de revisão prospetiva avançarem no que diz respeito à proteção dos sujeitos, os cientistas sociais em geral e os etnógrafos não estão contentes com os atuais moldes desta regulação. Há um ceticismo de que a regulação inspirada na ética biomédica vá melhorar a qualidade da investigação e que, pelo contrário, essa regulação pode atrapalhar o ritmo da investigação por encontrar incomensurabilidades de difícil ajuste; por isso é importante tomar estas experiências em conta, face à tendência e à possibilidade de vermos a implementação da regulação da investigação alargada aos demais países europeus, e em particular a Portugal, e nesse sentido importa garantir que, a haver revisão prospetiva, as particularidades da investigação qualitativa e etnográfica serão consideradas, protegidas e representadas. 
Mod.

\section{Estudo Observacional}

\section{Estudo sem intervenção medicamentosa}

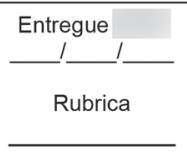

ESTUDO N.

IDENTIFICAÇÃO DO PROJECTO
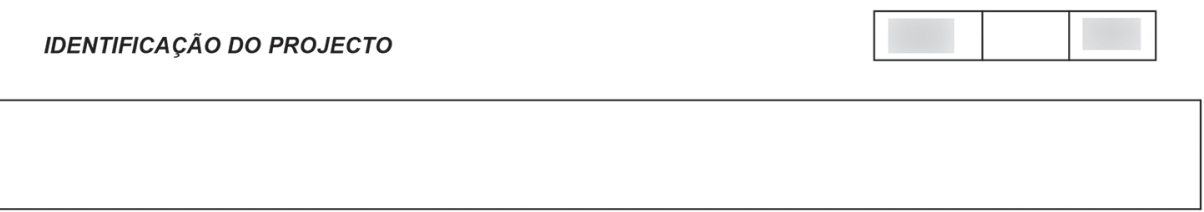

\begin{tabular}{|c|c|c|c|c|}
\hline ITEM & DESCRIÇÃO & $\begin{array}{c}\mathrm{N} .^{\circ} \\
\text { Exemp. }\end{array}$ & $\begin{array}{l}\text { Confirmado } \\
\text { pelo } \\
\text { Investigador }\end{array}$ & $\begin{array}{c}\text { Confirmado } \\
\text { pelo } \\
\text { Gabinete }\end{array}$ \\
\hline 1 & Pedido de autorização do estudo & 1 & & \\
\hline 2 & Identificação do Investigador & 1 & & \\
\hline 3 & Curriculum do investigador e co-investigadores (Datado e assinado) & 1 & & \\
\hline 4 & Autorização do director do serviço & 1 & & \\
\hline 5 & Parecer científico dado pelo Director do Serviço & 1 & & \\
\hline 6 & $\begin{array}{l}\text { Modelo específico da Comissão de Ética preenchido no que for } \\
\text { aplicável * }\end{array}$ & 1 & & \\
\hline 7 & $\begin{array}{l}\text { Documento de Informação ao doente e consentimento informado, em } \\
\text { português }\end{array}$ & 1 & & \\
\hline 8 & Projeto de Investigação & 2 & & \\
\hline 9 & Caderno de registo de dados - opcional & 1 & & \\
\hline 10 & $\begin{array}{l}\text { Declaração de que não constitui encargos financeiros adicionais para } \\
\text { o Hospital }\end{array}$ & 1 & & \\
\hline 11 & Toda a Documentação em Suporte Informático (CD) (Editável) & 1 & & \\
\hline
\end{tabular}

PARECER DA UNIDADE DE INOVAÇÃO E DESENVOL VIMENTO

PI'O Director da Unidade

1

(Prof. Doutor )

\section{NOTA:}

Todos os Documentos devem estar em Português.

Na apresentação do projecto de investigação deverá ser constituído um "dossier" com separadores identificadores dos pontos previstos no presente modelo. Esta documentacão deve ser enviada também em suporte informático, em formato editável.

Documento 1 - Lista de documentos requeridos. 

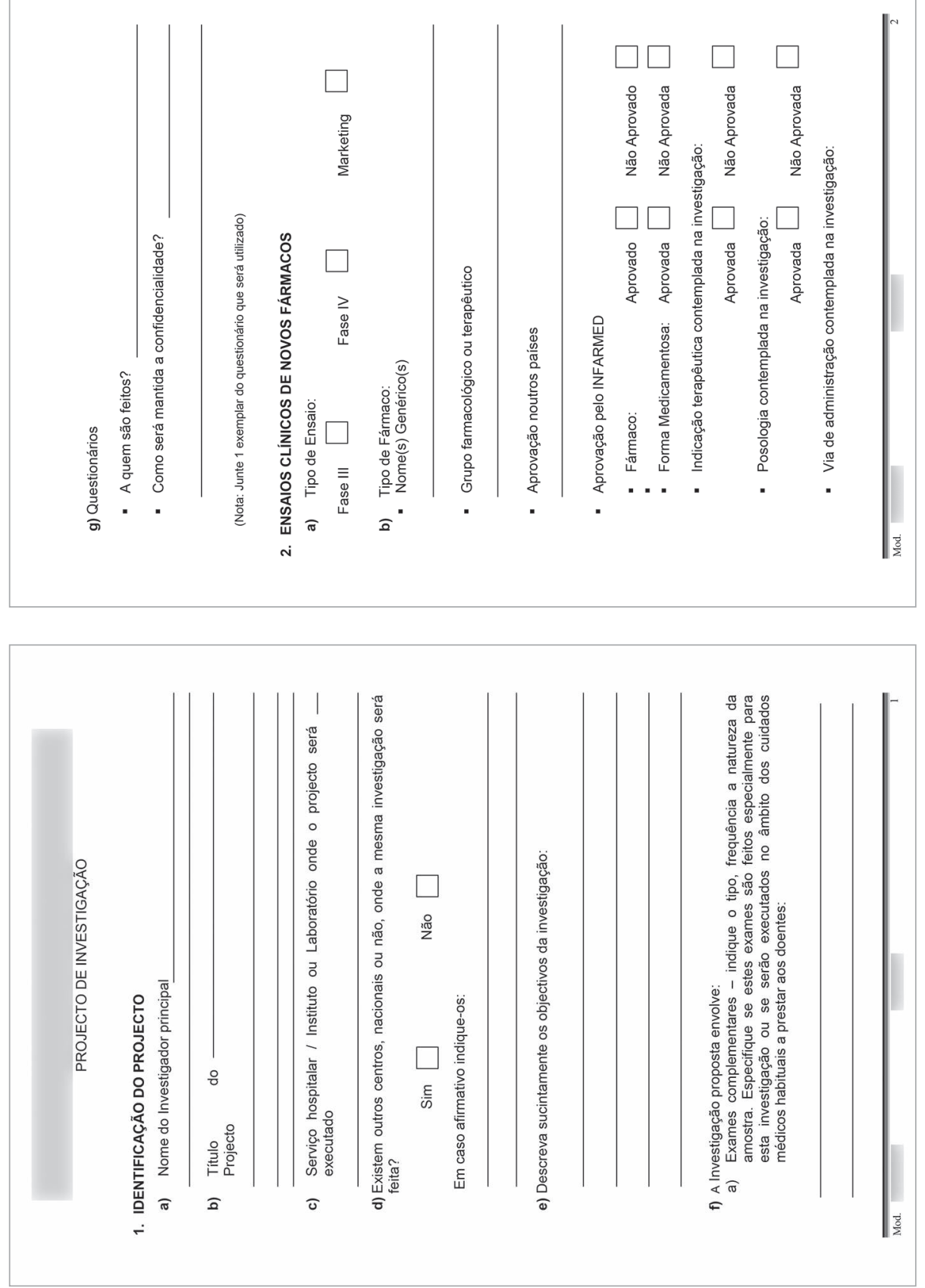

Documento 2 - Formulário (págs. 1 e 2). 

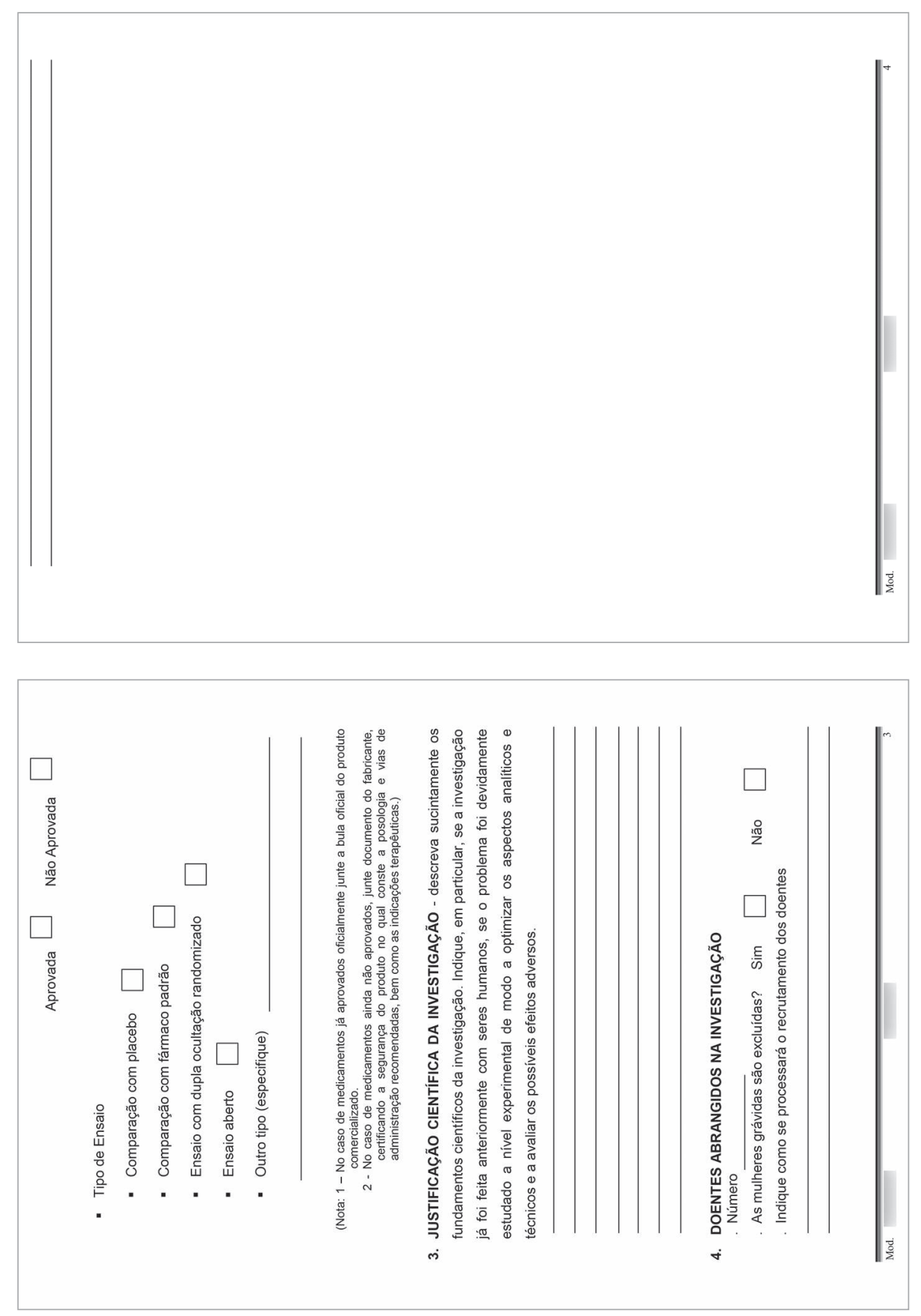

Documento 2 - Formulário (págs. 3 e 4). 

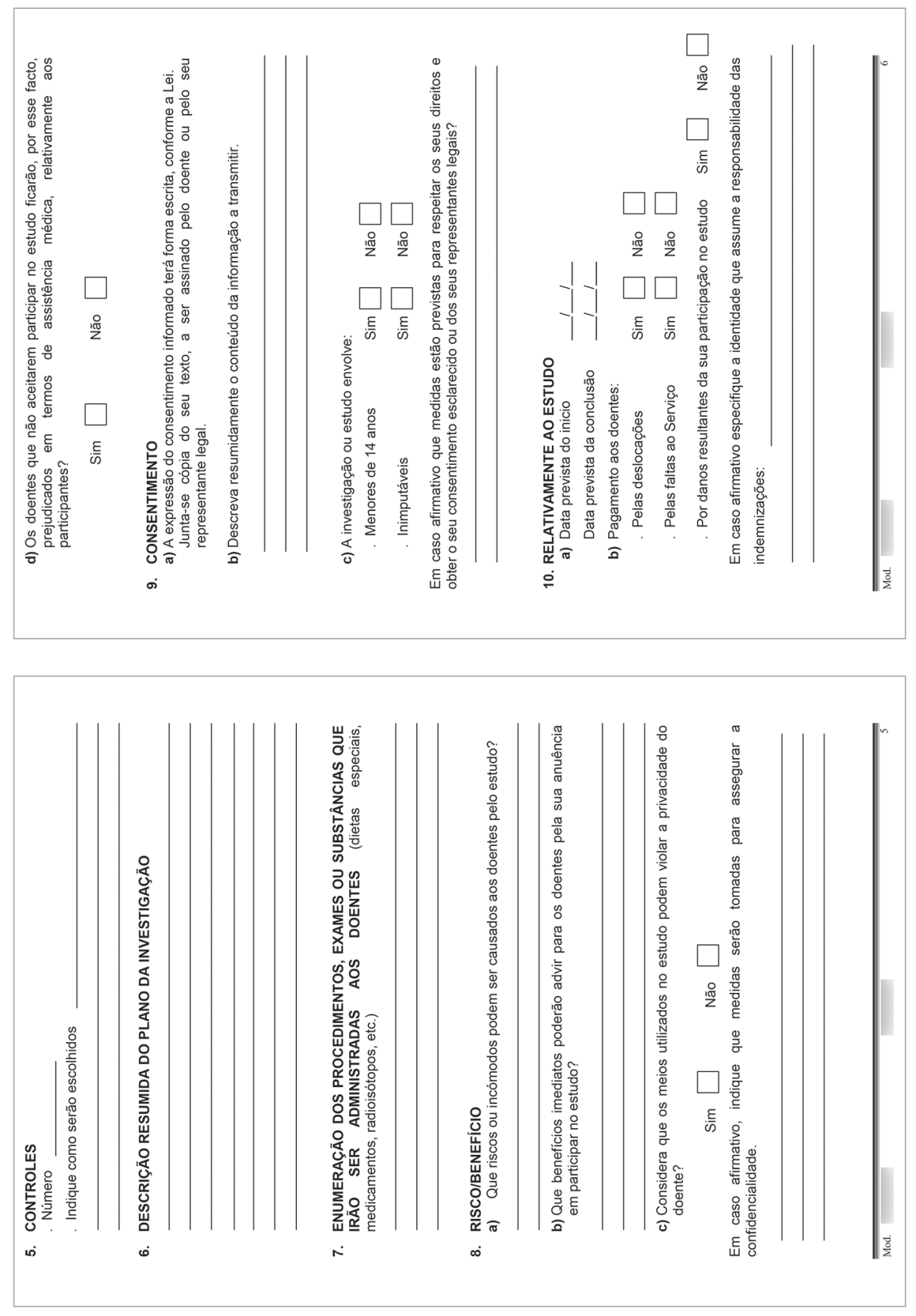

Documento 2 - Formulário (págs. 5 e 6). 

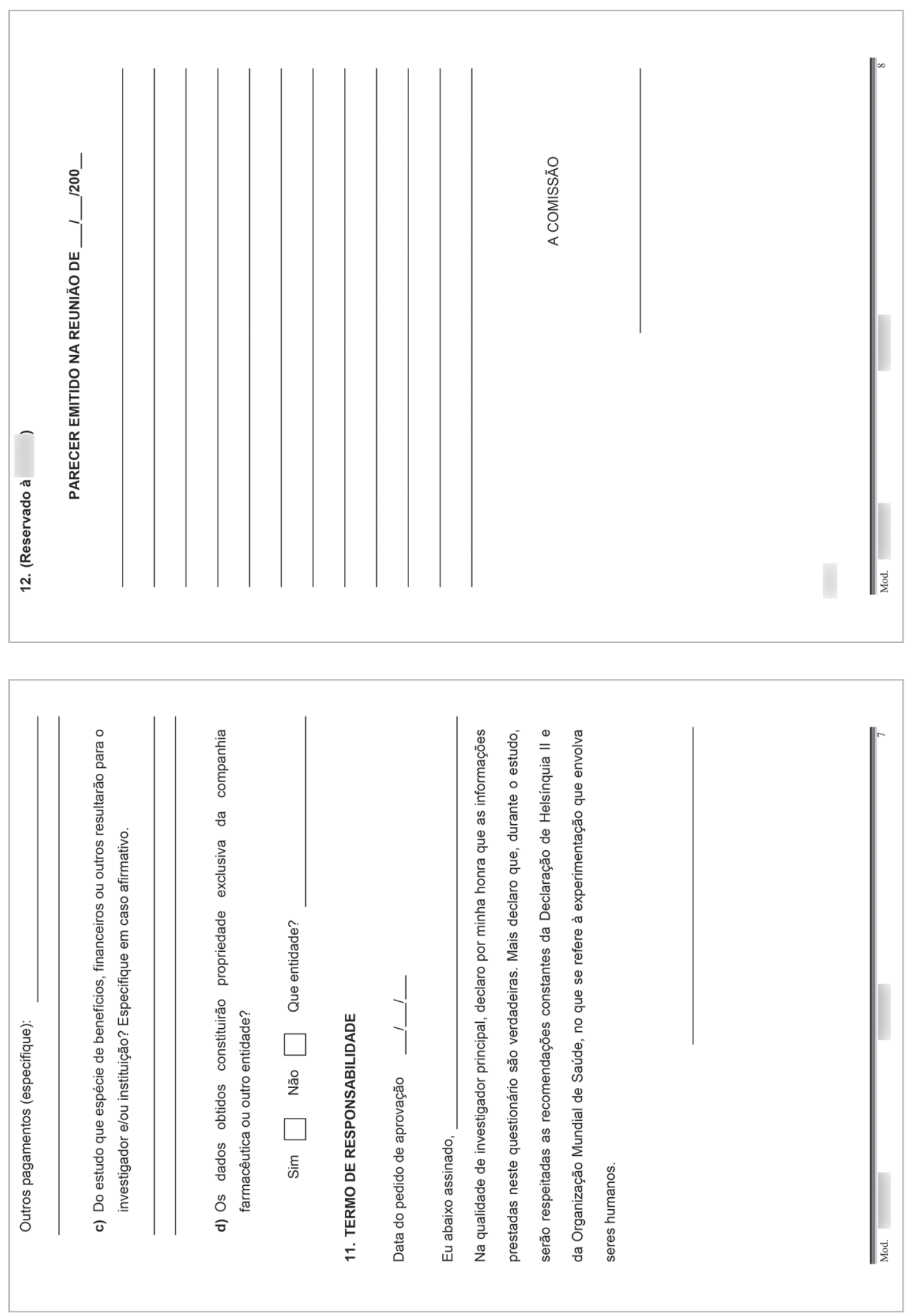

Documento 2 - Formulário (págs. 7 e 8). 


\section{BIBLIOGRAFIA}

BARTLETT, Edward, 2008, "International analysis of institutional review boards registered with the U.S. Office for Human Research Protections", Journal of Empirical Research on Human Research Ethics: An International Journal, 3 (4): 49-56.

BATTAGLIA, Debbora, 1999, "Toward an ethics of the open subject: writing culture in good conscience”, em Henrietta L. Moore (org.), Anthropological Theory Today. Cambridge, Polity Press, 1 14-150.

BOSK, Charles, e Raymond DE VRIES, 2004, "Bureaucracies of mass deception: institutional review boards and the ethics of ethnographic research", The Annals of the American Academy, 595: 249-263.

BOULTON, Mary, e Michael PARKER, 2007, "Informed consent in a changing environment", Social Science and Medicine, 65: 2187-2198.

BRUNER, Edward, 2004, "Ethnographic practice and human subjects review", Anthropology Newsletter, 45 (1): 10.

CAPlAN, Pat, 2003a, The Ethics of Anthropology: Debates and Dilemmas. Londres e Nova Iorque, Routledge.

CAPLAN, Pat, 2003b, "Introduction: anthropology and ethics", em Pat Caplan (org.), The Ethics of Anthropology: Debates and Dilemmas. Londres e Nova Iorque, Routledge, 1-34.

De LAINE, Marlene, 2000, Fieldwork, Participation and Practice: Ethical Dilemmas in Qualitative Research. Londres, Thousand Oakes e Nova Deli, Sage Publications.

DUARTE, Luiz F.D., 2004, "Ética de pesquisa e 'correção política' em antropologia”, em Ceres Víctora et al. (orgs.), Antropologia e Ética: O Debate Atual no Brasil. Niterói, EDUFF/ABA.

DUARTE, Luiz F.D., 2014, "Práticas de poder, política científica e as ciências humanas e sociais: o caso da regulação ética em pesquisa no Brasil”, História Oral, 17 (2): 9-29, disponível em <http://revista.historiaoral.org.br/index.php?journal=rho\&page $=$ article\& op=view\&path $\% 5 B \% 5 \mathrm{D}=401 \&$ path $\% 5 B \% 5 \mathrm{D}=\mathrm{pdf}>$ (última consulta em janeiro de 2017).

DUARTE, Luiz F. D., 2015, "A ética em pesquisa nas ciências humanas e o imperialismo bioético no Brasil", Revista Brasileira de Sociologia, 3 (5): 3 1-52, disponível em < http://www. sbsociologia.com.br/revista/index.php/RBS/article/view/90/64> (última consulta em janeiro de 2017).

FABIAN, Johannes, 1991, "Dilemmas in critical anthropology", em Lorraine Nencel e Peter Pels (orgs.), Constructing Knowledge: Authority and Critique in Social Science. Londres, Sage Publications, 180-202.

FASSIN, Didier, 2006, “The end of ethnography as collateral damage of ethical regulation?”, American Ethnologist, 33 (4): 522-524.

FLEISCHER, Soraya, e Patrice SCHUCH (orgs.), 2010, Ética e Regulamentação na Pesquisa Antropológica. Brasília, Letras Livres/Editora Universidade de Brasília.

FLUEHR-LOBBAN, Carolyn, 1991, Ethics and the Profession of Anthropology: Dialogue for a New Era. Filadélfia, University of Pennsylvania Press.

FONSECA, Claudia, 2015, "Situando os comitês de ética em pesquisa: o sistema CEP (Brasil) em perspectiva”, Horizontes Antropológicos, 21 (44): 333-369.

FREED-TAYLOR, Marcia, 1994, "Ethical considerations in European cross-national research", International Social Science Journal, 46 (4): 523-532. 
GEERTZ, Clifford, 1973, The Interpretation of Cultures. Nova Iorque, Basic Books.

GUILLEMIN, Marylis, e Lynn GILLAM, 2004, "Ethics, reflexivity, and 'ethically important moments' in research", Qualitative Inquiry, 10: 261-280.

KOMESAROFF, Paul A., 1995, "From bioethics to microethics: ethical debate and clinical medicine", em Paul A. Komesaroff (org.), Troubled Bodies: Critical Perspectives on Postmodernism, Medical Ethics and the Body. S/l., Duke University Press, 62-86.

LAVE, Jean, e Etienne, WENGER, 1991, Situated Learning: Legitimate Peripheral Participation. Cambridge, Cambridge University Press.

LEDERMAN, Rena, 2006a, "Introduction: anxious borders between work and life in a time of bureaucratic ethics regulation", American Ethnologist, 33 (4): 477-481.

LEDERMAN, Rena, 2006b, “The perils of working at home: IRB 'mission creep' as context and content for an ethnography of disciplinary knowledges”, American Ethnologist, 33 (4): 482-491.

LEWIS, Graham, et al., 2004, “The international dimension to research ethics: the significance of international and other non-UK frameworks for UK social science", Economic and Social Research Council Research Ethics Framework, discussion paper n. ${ }^{\circ} 2$, disponível em < http://www.york.ac.uk/res/ref/docs/REFpaper2_v2.pdf > (última consulta em janeiro de 2017).

LIFTON, Robert, 2000, The Nazi Doctors: Medical Killing and the Psychology of Genocide. Nova Iorque, Basic Books.

MACDONALD, Helen, e Andrew SPIEGEL, 2013, “'Distraction from the real difficulties': ethical deliberations in international health research", Anthropology Southern Africa, 36 (3-4): 146-154.

MACHADO, Lia Z., 2007, Ética em Pesquisa Biomédica e Antropológica: Semelhanças, Contradições, Complementaridade. Brasília, Letras Livres/Editora da Universidade de Brasília.

MARCUS, George E., 1995, "Ethnography in/off the world-system: the emergence of multisited ethnography”, Annual Review of Anthropology, 24: 95-1 17.

MARCUS, George E., 1998, Ethnography through Thick and Thin. Nova Jérsia e West Sussex, Princeton University Press.

MILLER, Tine, e Linda BELL, 2002, "Consenting to what? Issues of access, gate-keeping, and informed consent", em Melanie Mauthner et al. (orgs.), Ethics in Qualitative Research. Londres, Sage Publications, 53-69.

NUNES, João Arriscado, 2011 , "Sobre a ética (e a política) da investigação social em saúde", Sociologia On Line, 3: 167-188, disponível em < http://revista.aps.pt/cms/files/artigos pdf/ART4e66506fb7 lbl.pdf > (última consulta em janeiro de 2017).

PARKER, Michael, 2007, "Ethnography/ethics", Social Science and Medicine, 65: 2248-2259.

PELS, Peter, 1999, "Professions of duplexity: a prehistory of ethical codes in anthropology", Current Anthropology, 40 (2): 101-136.

PELS, Peter, e Lynn MESKELL, 2005, Embedding Ethics: Shiffting Boundaries of the Anthropological Profession. Oxford, Berg.

RIBEIRO, Gustavo L., 2006, "IRBs are the tip of the iceberg: State regulation, academic freedom and methodological issues", American Ethnologist, 33 (4): 529-531.

SARTI, Cynthia, 2015, "A ética em pesquisa transfigurada em campo de poder: notas sobre o sistema CEP/Conep", Revista Brasileira de Sociologia, 3 (5), disponível em < http://www. sbsociologia.com.br/revista/index.php/RBS/article/view/94 > (última consulta em janeiro de 2017). 
SARTI, Cynthia, e Luiz F. D. DUARTE (orgs.), 2013, Antropologia e Ética: Desafios para a Regulamentação. Brasília, ABA Publicações.

SCHEPER-HUGHES, Nancy, 1995, "The primacy of the ethical: proposition for a militant anthropology”, Current Anthropology, 36 (3): 409-440.

SHORE, Chris, e Sue WRIGHT, 1999, "Audit culture and anthropology: neo-liberalism in British higher education”, Journal of the Royal Anthropological Institute, 5 (4): 557-576.

SIMPSON, Bob, 2011 , "Ethical moments: future directions for ethical review and ethnography”, Journal of the Royal Anthropological Institute, 17: 377-393.

SOLOVEY, Mark, 2001, "Project Camelot and the 1960s epistemological revolution: rethinking the politics-patronage-social science nexus", Social Studies of Science, 31 (2): $171-206$.

STRATHERn, Marylin, 2000, Audit Cultures: Anthropological Studies in Accountability, Ethics and the Academy. Londres e Nova Iorque, Routledge.

VíCTORA, Ceres, et al. (orgs.), 2004, Antropologia e Ética: O Debate Atual no Brasil. Niterói, EDUFF/ABA.

WMA - WORLD MEDICAL ASSOCIATION, 2008, Declaration of Helsinki: Ethical Principles for Medical Research Involving Human Subjects, disponível em < http://www.wma.net/ en/30publications/10policies/b3/17c.pdf > (última consulta em janeiro de 2017). 